\title{
Malignant pilomatricoma of the cheek in an infant
}

\author{
Yang Seok Kim, \\ Young Cheon Na, \\ Woo Hoe Huh, \\ Ji Min Kim \\ Department of Plastic and \\ Reconstructive Surgery, Wonkwang \\ University Hospital, Iksan, Korea
}

\begin{abstract}
Malignant pilomatricoma (pilomatrical carcinoma) is a rare, locally occurring malignant tumor with a high rate of recurrence in the case of incomplete excision. This tumor has two characteristics. First, recurrences of pilomatrical carcinoma are common; second, distant metastasis is rare, but if it occurs, it is very fatal. It has characteristic features of high mitotic counts, cellular atypia, and local invasion. Although fine needle aspiration and excisional biopsy could help to confirm this tumor diagnosis, pathologic findings are critical. Pilomatricomas have some characteristic features in histological aspect, such as epithelial islands of basaloid cells and shadow cells or ghost cell. Also, various types of immunohistochemical staining are used to confirm the diagnosis. Despite the lack of clear surgical criteria, treatment is a wide local excision with histologically clear resection margins with or without adjuvant radiotherapy.
\end{abstract}

Keywords: Facial neoplasm / Malignant pilomatricoma / Pilomatricoma / Pilomatrixoma

\section{INTRODUCTION}

Malignant pilomatricoma (pilomatrical carcinoma) is a rare, locally occurring malignant tumor with a high rate of recurrence in the case of incomplete excision [1,2]. The first report that described malignant pilomatricoma was published in 1980. In 2017, Otero et al's review [3] found only 136 cases that had been reported in English-speaking literature worldwide. Local recurrence rate is rather high, but distant metastasis is rare. The histological features of pilomatrical carcinoma are high mitotic counts, cellular atypia, and local invasion [4]. Despite the lack of clear surgical criteria, treatment is a wide local excision with a histologically clear resection margins with or without adjuvant radiotherapy. In this study, we report a case of malignant pilomatricoma in an infant's cheek.

Correspondence: Young Cheon Na

Department of Plastic and Reconstructive Surgery, Wonkwang University Hospital, 895 Muwang-ro, Iksan 54538, Korea

E-mail: ycnadr@hanmail.net

Received September 11, 2018 / Revised October 31, 2018 / Accepted November 2, 2018

\section{CASE REPORT}

A 8-month-old boy presented with a 3-month history of erythematous nodule with a mild swelling and serous discharge in the right cheek. A patient had no specific medical singularities or congenital anomalies. At birth, there were no marks on his face. We decided to evaluate the patient with nonaggressive tools first. Ultrasonography showed a well-defined, oval-shaped hypoechoic $0.5 \times 0.7-\mathrm{cm}$-sized nodule with calcification and a hypervascular lesion (Fig. 1). The clinical and assumed diagnosis was hemangioma. As the patient had inflammation on the right cheek, we prescribed parental antibiotics and did a followup. Five days later, erythema and swelling subsided, and we planned an excisional biopsy with general anesthesia.

In operation, there was a mass $1.0 \times 1.0 \mathrm{~cm}$ in size with necrotizing lesions and calcification (Fig. 2). There were no vascular components, and the mass was passed to a pathologist. As the total excision was made, the defect was covered by a local advancement flap (Fig. 3). After surgery, the patient had an uneventful recovery, but histologic examination revealed malignant pilomatricoma with infiltrative borders, atypical cytologi- 


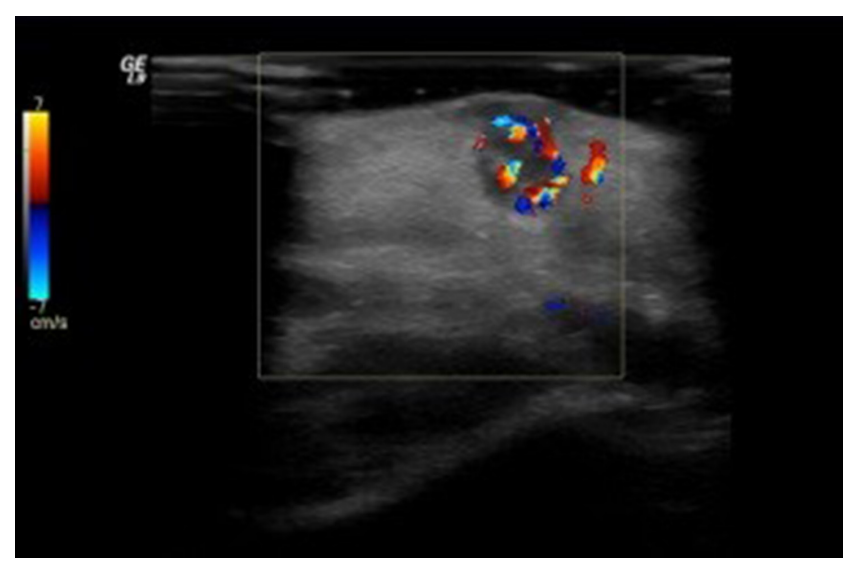

Fig. 1. Ultrasonography showed a well-defined, oval-shaped hypoechoic $0.5 \times 0.7-\mathrm{cm}$-sized nodule with calcification and hypervascular lesion.

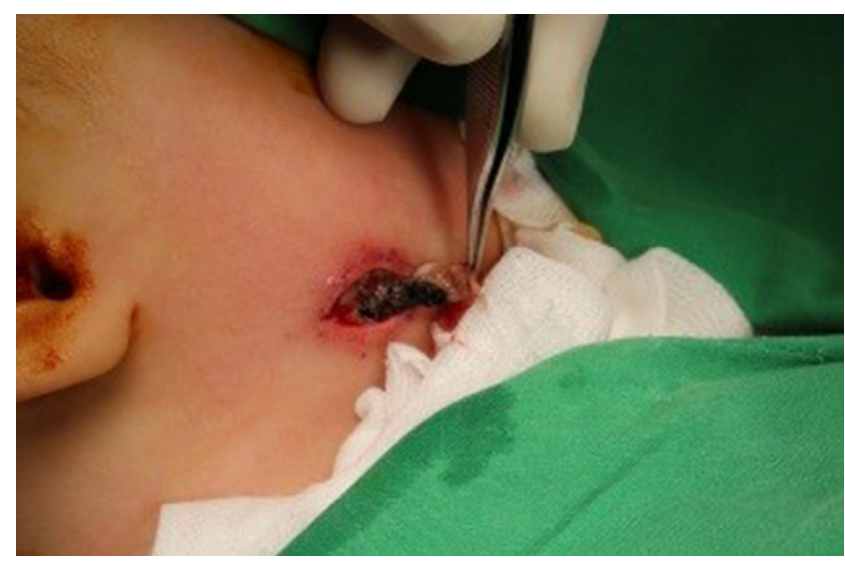

Fig. 2. In operation, a mass with necrotizing lesion and calcification was biopsied. The mass was $1.0 \times 1.0 \mathrm{~cm}$.

cal features, and high mitotic rate (Fig. 4). Also, the tumor was composed with basaloid cells with central necrosis. Within the necrosis, some shadow cells were found. Basaloid cells reveled polymorphism and atypia with a high mitotic rate and also contained calcification, confirming a diagnosis of malignant pilomatricoma. However, histologic analyses showed no vascular or lymphatic involvement.

To complete staging, an enhanced computed tomography (CT) scan was performed (Fig. 5). No enlarged nonnecrotic lymph node either in retropharyngeal space or in the neck level was found. There was no lytic or blastic bone lesion in the skull and the facial bone. Furthermore, in a simple chest X-ray, no signs of any metastasis were observed. Therefore, we planned further excision; the lesion was removed with a 1-cm margin and covered with a local advancement flap. No residual tumor was evident on histopathology. We consulted a hematologist, but no additional adjuvant therapy was done, and there were no signs of recurrence after a year.

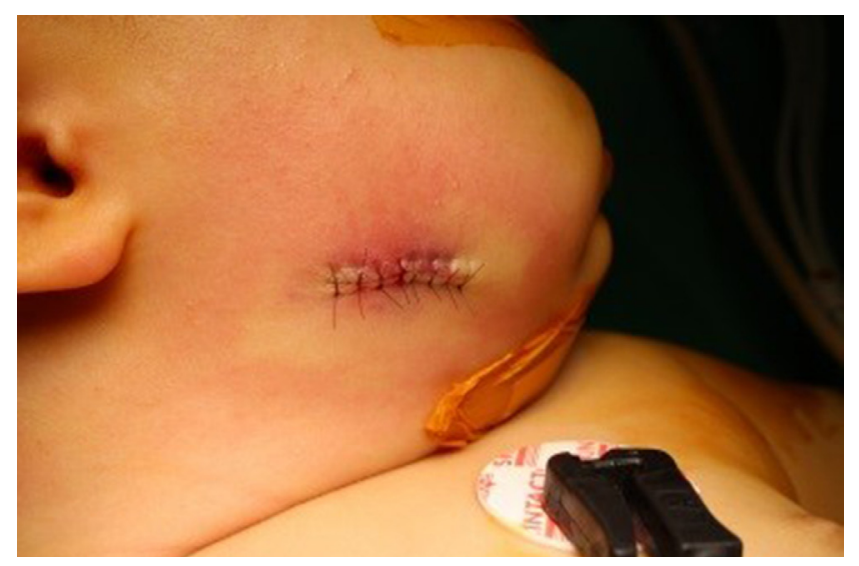

Fig. 3. After tumor resection, the defect was covered by local advancement flap with layer by layer closure.

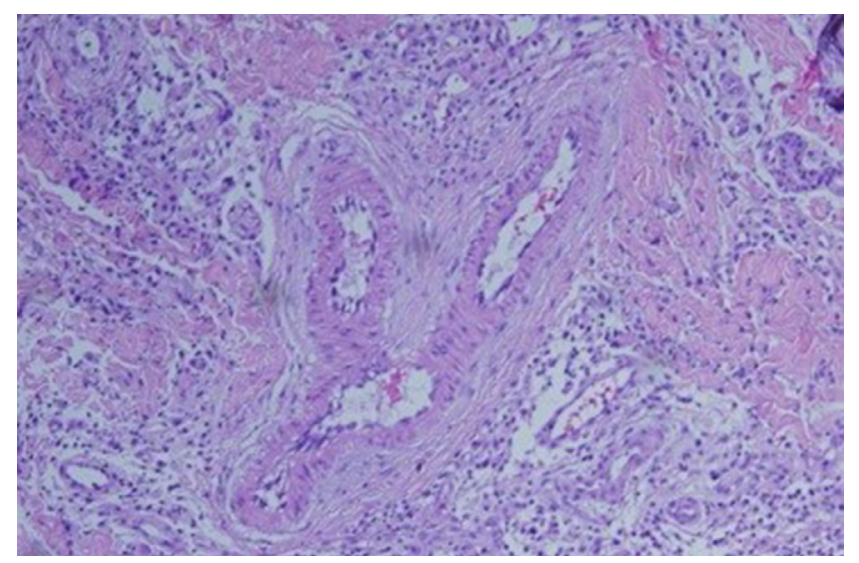

Fig. 4. Histologic examination revealed malignant pilomatricoma with infiltrative borders, atypical cytologic features and high mitotic rate $(\mathrm{H} \& \mathrm{E}, \times 200)$.

\section{DISCUSSION}

Pilomatricoma, a common adnexal tumor that differentiates towards hair cortex cells, is usually benign and rarely invasive. Malignant changes of pilomatricoma were first described as a malignant pilomatricoma or calcifying epitheliocarcinoma of Malherbe [1]. This tumor is usually of the insidious nature, and also it is difficult to distinguish it from benign adnexal tumors. Locally aggressive and low grade are the features of malignant pilomatricoma [5].

The main presentation of pilomatricoma is asymptomatic and firm nodules with mobility. The size of the mass varies from 1 to $10 \mathrm{~cm} \mathrm{[6].} \mathrm{This} \mathrm{tumor} \mathrm{is} \mathrm{located} \mathrm{in} \mathrm{deep} \mathrm{dermis} \mathrm{to} \mathrm{subcutis}$ and epidermal invasion is rare [7]. It has a predilection for the scalp, face, posterior neck, upper back, upper extremities, and the preauricular area. In contrast to the benign lesion, malignant counterpart is mostly observed in older patients, with the 

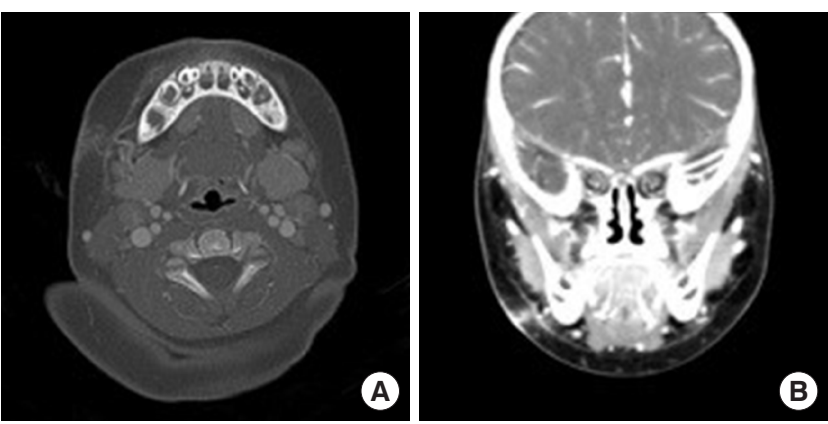

Fig. 5. (A, B) Enhanced computed tomography scan was proceeded. No enlarged nonnecrotic lymph node either in retropharyngeal space or in neck level was founded.

male to female ratio of 5:1; the patient age ranges from 8 to 93 years (mean age, 52 years) [5,8-12]. Metastases are reported in $10 \%$ of cases, and major sites of metastasis are lungs, bones, and regional lymph nodes [7].

Usually, pilomatricoma is misdiagnosed as a dermoid and epidermoid cyst, hemangioma, basal cell carcinoma, or squamous cell carcinoma [13]. Some studies suggested that there is some possibility for a precursor lesion that includes the nevus sebaceous or the residual benign pilomatricoma. However, it is not clear whether malignant pilomatricoma is derived from a benign one through malignant transformations or not. Furthermore, it is also difficult to differentiate benign and malignant pilomatricoma clinically [5].

However, compared to benign pilomatricomas, malignant pilomatricomas, as revealed in several studies, contained mutations of exon 3 of the CTNNB1 gene [9]. Pilomatricomas have some characteristic histological features, such as epithelial islands of basaloid cells, shadow cells, or ghost cells. The basaloid cells have basophilic oval or round nuclei. Deposits of basophilic calcium can also be seen; thus calcification occasionally occurs [14].

Histologically, the diagnosis of malignant pilomatricoma can be challenging. There are no clear histologic criteria distinguishing this tumor from other matrical tumors. However, the key differentiating aspect is mitotic rate [13]. In general, a pilomatrical carcinoma usually exhibits cellular pleomorphism, prominent nucleoli, and an increased mitotic rate up to 20 per high power field [6]. In order to diagnose a malignant pilomatricoma, various types of immunohistochemical staining are used to confirm the diagnosis. Fine needle aspiration biopsy is considerable in preoperative evaluation to distinguish a pilomatrical carcinoma from a tumor; however, cytological results showed malignancy only in aspiration cells. This means that needle aspiration cytology is not useful in differential diagnosis of pilomatricoma and malignant pilomatricoma [14]. Imaging studies including computed tomography or magnetic resonance image (MRI) can be useful for the evaluation of malignant pilomatricoma and for determining the bony invasions. However, there are no clear radiological and morphological criteria, as repeated CT scans and ultrasonography were inconclusive.

In the literature, treatment for pilomatrical carcinomas is a wide local excision with histologically clear resection margins. Because this tumor is locally aggressive, key role of preventing local recurrence is to secure surgically clear safety margin. Most authors recommend resection of this tumor with at least 5-10 $\mathrm{mm}$ safety margin $[5,7]$. The recurrence rate of cases of a simple excision exceeds $50 \%$. On the other hand, a complete wide excision of this tumor is associated with a low rate of recurrence. Treatment by Mohs micrographic surgery may be an option to consider as well. In the case Mohs surgery, it is possible to use precise margin control [15].

It is recommended that postoperative radiotherapy be done in the case of recurrence or a residual macroscopic tumor. However, the data for dosage of radiotherapy or therapeutic result remains unclear. With regard to the effect of chemotherapy, there are no regimens for an effective local control or modifying the course of the disease $[1,16]$. Although adriamycin and ifosfamide could be applied for nonmetastatic malignant pilomatricoma patients, the effectiveness of this formula remains questionable [17]. To check-up the recurrence, major tools are a regular follow-up for several years after treatment and physical exams. If any stigma or symptoms appear, the MRI scan or ultrasonography could be used. Also, any suspicious mass could be biopsied for surveillance. Distant metastasis is rare. However, if it occurs, it is fatal. Therefore, a regular follow-up by a clinician is crucial.

\section{CONFLICT OF INTEREST}

No potential conflict of interest relevant to this article was reported.

\section{PATIENT CONSENT}

The parents of the patient provided written informed consent for the publication and the use of his images.

\section{ORCID}

Yang Seok Kim https://orcid.org/0000-0003-3161-7284

Young Cheon Na https://orcid.org/0000-0003-3136-0351

Woo Hoe Huh https://orcid.org/0000-0002-1379-7122

Ji Min Kim https://orcid.org/0000-0002-9819-0775 


\section{REFERENCES}

1. Lopansri S, Mihm MC Jr. Pilomatrix carcinoma or calcifying epitheliocarcinoma of Malherbe: a case report and review of literature. Cancer 1980;45:2368-73.

2. Tateyama H, Eimoto T, Tada T, Niwa T. Malignant pilomatricoma: an immunohistochemical study with antihair keratin antibody. Cancer 1992;69:127-32.

3. Otero MN, Trujillo CP, Parra-Medina R, Morales SD. Metastatic malignant pilomatrixoma in an 8-year-old girl misdiagnosed as a recurrent pilomatrixoma. Am J Dermatopathol 2017;39:e41-3

4. O’Donovan DG, Freemont AJ, Adams JE, Markham DE. Malignant pilomatrixoma with bone metastasis. Histopathology 1993;23:385-6.

5. Hardisson D, Linares MD, Cuevas-Santos J, Contreras F. Pilomatrix carcinoma: a clinicopathologic study of six cases and review of the literature. Am J Dermatopathol 2001;23:394-401.

6. Sau P, Lupton GP, Graham JH. Pilomatrix carcinoma. Cancer 1993;71:2491-8.

7. Petit T, Grossin M, Lefort E, Lamarche F, Henin D. Pilomatrix carcinoma: histologic and immunohistochemical features. Two studies. Ann Pathol 2003;23:50-4.

8. Zachariades N, Mezitis M, Rallis G, Panoussis P, Machera H, Velmachou K. Vascular malformations in a 3(1/2)-year-old child. Oral Surg Oral Med Oral Pathol Oral Radiol Endod 2001;91:271-3.
9. Lazar AJ, Calonje E, Grayson W, Dei Tos AP, Mihm MC Jr, Redston $\mathrm{M}$, et al. Pilomatrix carcinomas contain mutations in CTNNB1, the gene encoding beta-catenin. J Cutan Pathol 2005;32:148-57.

10. Sloan JB, Sueki H, Jaworsky C. Pigmented malignant pilomatrixoma: report of a case and review of the literature. J Cutan Pathol 1992;19:240-6.

11. Sable D, Snow SN. Pilomatrix carcinoma of the back treated by Mohs micrographic surgery. Dermatol Surg 2004;30:1174-6.

12. Caubet-Biayna J, Ramos-Asensio R, Ortabe I, Mas M. Pilomatrix carcinoma of the face. J Oral Maxillofac Surg 1999;57:60911.

13. Zachariades N, Mezitis M, Rallis G, Spyrou A, Machera H. Malignant pilomatricoma in a child with a previous vascular malformation. Br J Oral Maxillofac Surg 2008;46:152-3.

14. Kondo T, Tanaka Y. Malignant pilomatricoma in the parietal area. Pathol Oncol Res 2006;12:251-3.

15. Sassmannshausen J, Chaffins M. Pilomatrix carcinoma: a report of a case arising from a previously excised pilomatrixoma and a review of the literature. J Am Acad Dermatol 2001;44(2 Suppl):358-61.

16. Duarte VM, Sepahdari AR, Abasolo PA, St. John M. Pilomatrix carcinoma of the head and neck: case report and review of the literature. Int J Otolaryngol Head Neck Surg 2012;1:53-6.

17. Tselis N, Heyd R, Vogt HG, Zamboglou N. Pilomatrix carcinoma with lymph node and pulmonary metastases. Strahlenther Onkol 2006;182:727-32. 